It will be noted that the suggestions were not all made at once, but successively, as her condition demanded, and always with a distinct appreciation of the physiologic processes which should be stimulated or controlled in order to bring about the desired result. In making the suggestions it was not sought to use language adapted to the comprehension of the patient in her normal condition, and that used was never heard by her or at least never became a part of her usual consciousness.

I will not give a needless detail of cases, though they could easily be multiplied. I simply wish to call attention to the fact that in a great variety of cases and a multitude of instances physiologic processes have been influenced and controlled by suggestion.

Numerous cases have been reported by Liébault, Bernheim, Leigois, Dumontpallier, Burru, KrafftEbing and many others, where suggestion has produced changes in the physiologic processes of the body; changes in the heart's action, in temperature, in the vascular and vasomotor systems, causing the raising of blisters, bleeding from the nose or oozing of blood from designated points upon the surface of the body, and increasing or diminishing the various secretions of the body. With the knowledge of such facts before us, stigmatization, the reported cases of which now exceed 100, ranging from St. Francis of Assisi in the thirteenth century to Louise Lateau at the present time, becomes credible, and may be studied with interest and profit, and without loss of caste, even by persons of rigorous scientific orthodoxy. In fact, the old adage, "There is nothing that makes a man suspect, more than to know little," is most applicable to the matters here presented.

The field then in which hypnotism and suggestion are effective and may be made useful is not limited to nervous or imaginary diseases, but extends to a large class of functional disorders, and in some cases at least, and under some favorable circumstances, to serious organic disease; and the assistance rendered by suggestion in these cases is perfectly natural and scientific, and is due to its influence upon physiologic processes, stimulating, retarding and regulating with a certainty and success, varying according to the susceptibility of the patient and the knowledge and skill of the physician.

\section{HYPNOTISM IN THE TREATMENT OF DISEASE.}

Presented to the Section on Neurology and Medical Jurisprudence, a the Forty-eighth Annual Meeting of the American Medical Association, held at Philadelphia, Pa., June 1-4, 1897.

BY U. O. B. WINGATE, M.D., M.M.S.S.

Professor of Diseases of the Nervous system, Wisconsin College of Physician. and Surgeons, Visiting Physician to St. Mary's Hospital, Consultant in Neurology, Presbyterian Hospital, etc. MILWAUKEE, WIS.

From the earliest period in the history of the heal. ing art, there has always been a strong tendency to accept any mysterious or unknown agency in the treatment of disease; more especially is this acceptance favored by the less learned in science, and among those afflicted there is always found a large clientage who are ready to be operated on by anything surrounded by mystery or pertaining in any way to the occult.

Hypnotism, undoubtedly, owes to the mysticism that surrounds it its existence and practice. If it were better understood, no doubt it would be neglected and soon forgotten with the host of other agencies. that have existed in the past and lost their charm as they became understood.

To the scientific physician it fails to create confidence enrough to be of much use, and its employment. is now apparently largely in the hands of that class of practitioners who seem to play on the credulity of the public more than to treat disease in a strictly scientific. manner. I am well aware that I am open to severe criticism by some, but I base my statements upon my own experience and observation. With a large acquaintance with practicing members of my profession, I have failed to find but few who care to make use of hypnotism as an agency in their practice, and those who do use it appear to do so more as an experiment than as honest scientific treatment. In the use of it myself I have always felt some degree of guilt, and am sure I could have accomplished similar results with agents. that are more scientific, more satisfactory, and with a feeling that $I$ have not left behind conditions that may be harmful, for I am sure that the results of the use of hypnotism, in many instances, may be harmful.

If the nature of hypnotism be such as Maudsley describes, and I see no good reason to doubt his conclusions, surely we should think long and carefully before employing it in our practice. He says:

"What may we suppose to take place when a person is thrown into such a trance in which, machinelike, he is governed by suggestions which the operator makes, touching, tasting, seeing, hearing, thinking and doing just as he is bid? That by the special suggestions made, the fit tracts of his brain are stimulated to a separate and pretty nigh exhaustive activity, while the functions of the remaining tracts are suspended. Thereupon he can not choose but perceive as he has been made to think; must translate every impression on sense into the language of the solely activeidea, and shape to its features, or else have no consciousness of it at all. He can not possibly perceive in the terms of ideas that are entirely inactive. The one active cerebral tract is virtually the whole and sole mind which he then has, and to obey it in sense and act is a compulsive necessity. For the time being he is effectually severed from full mental contact with things as if he had been educated through life to exer. cise that tract and none other, or as if he were a mad. man, dominated by its morbid growth and function There is good reason then, why persons of weak and unstable nervous temperaments can, while persons of strong, compact mental organism can not, be thus put out of possession of themselves, and why those who have frequently allowed their mental being to be thus dislocated become so unstable, at least as to fall out of mental joint at the least suggestion. Nay more, thereare persons who under enthusiasm, or other mental. excitement, can perform a self-hypnotism, and afterward so cultivate the acquired function by strain and. practice, as to repeat the operation at will, with the greatest ease." Such is the character of this agency, which no doubt has existed as long as the history of the treatment of disease varying in degree of potency in different ages and under different conditions of the human family.

That we are living in an age where from the activity and strife and strain of life, in a severe struggle for position and existence, coupled with a heredity that is becoming more and more conspicuous, when there is. 
great weakness of the human mind and tendency to nerve deterioration and mental clecay, no one who carefully studies the events of the times can fail to observe. This condition produces a large train of human minds that crave leadership, in other words, minds easily influenced by suggestion; hence we see hypnotism more easily practiced than in some other periods in our history. Human credulity seerns to be at its highest point, the great masses of the people are capable of being easily led by the suggestions of the few, and such a condition can not be considered as a healthy one in the body politic. If it be true that by the practice of this agency, we weaken the subjective mind instead of giving it strength, if by repeated suggestions it becomes more and more easily affected, and dependent, surely such treatment can not be of advantage to the subject, but on the other hand, we are increasing the weakness of the will of the individual, and surely in this direction madness and mental decay lie.

To quote again from Maudsley, relative to hypnotism: "The compact consciousness of the supreme cen" ters has become broken up, a discordant tendency fostered, and the disassociated centers are prone to continue their abnormal and independent action. This state frequently follows too oft repeated hypnotic experiments in the same individual, and assuredly that way madness lies."

Charcot said nothing of the therapeutic uses of hyp. notism. He indeed pointed out that a woman who had hysterical paralysis of one leg, walked about and seemed cured during hypnosis, and that though he might temporarily remove the paralysis by suggesting its disappearance, that such a remedy did not treat the disease she labored under, but only allayed one symptom. He treated his cases of hysteria according to the best principles known, namely, seclusion, fattening foods, and the physiologic mode of living.

Dr. Robertson states that it is the general opinion of the medical profession in Nancy that while hypnotism has done some good, in many instances its general affect is more harmful than beneficial, inasmuch as the general belief by people in occult powers, and the power of one man's mind over the conduct of others weakens will power and thus becomes injurious.

There is no doubt but that outrage can be effected in the hypnotic condition, and although it may be doubted if crime can be committed, it seems that the weight of evidence is largely in that direction.

All writers on the subject condemn public exhibitions of this practice, and I believe the time will soon come when its use by the medical profession will entirely give way, as I believe it should, to safer and more scientific methods of practice, and by other ther apeutic agents.

\section{Biddle Street.}

DISCUSSION ON PAPERS OF DRS. MASON AND WINGATE

Dr. T. D. Crothers-Suggestion is a physiologic, and not a pathologic process. I believe it is more absolutely certain than Rochelle salts or any other medicine that we are in the habit of using. I know that no man can practice medicine without suggestion; you may call it personality, or magnetism, or may attempt to define it, but in reality it is suggestion.

Dr. TwITCHELL-In the last few months I have written 100 letters to leading psychologists, both in this country and in Europe, and have received 41 answers, only 2 of which were opposed, not only to the use, but to a better teaching of this subject in our medical colleges. Solomon Solis.Cohen of this city wrote that he believed in an all-round study of the mental faculty both in disease and in its cure. I believe the time is coming when, not only will every physician throughout th land recognize this factor in treatment, but it will be taught in all our medical colleges. As to the injury done by hypnotism, how many of us are absolutely certain that any of our druge does not produce evil effects? How many of us will use morphia, or any potent drug, and feel absolutely certain that in any given case he will produce no injury?

Dr. MOYER-I do not see the great dangers to be apprehended from hypnotism, and I suspect that suggestion, which I think is really what is understood by hypnotism, has been used almost from time immemorial, and that it explains a vast deal of the phenomena in the nervous system in disease which is not ex. plicable on any other theory. It is only of late that I have been employing hypnotism at all extensively, and it is almost routine practice with me to hypnotize about all the patients that come to my clinic. I have yet to see any bad results. The number of cures that have been effected in this way is quite numerous. I can recall one striking case of hysteric paraplegia in a man who was brought to my clinic with great difficulty, partly carried up the stairway, and before he left was able to walk down the stairway. A nother, an hysteric hemiplegic who had not been employed for four years, has resumed his work after four treatments of hypnotic suggestion. Suggestion has a wider range than that. Even in organic affections the patient becomes more hopeful and confident, and his general condition improves.

Dr. Mason-I had supposed that all were accustumed to look upon hypnotism as a fact, and one which we are gradually learning to apply scientifically, by means of methods of observation and drawing conclusions. Any statements in regard to the physical effects of hypnotism upon the brain are purely hypothetic, and there are no facts upon which to base any statement of this kind. Of course, from continuous hypnotism of one subject we might possibly have uncomfortable effects, but this is true of almost any other therapeutic procedure. I have used hypnotism twenty years, commencing before Charcot and Bernheim, and in all that time I have never seen an untoward effect of any sort whatever. Charcot endorsed hypnotism, and made use of it.

Dr. WINGATE - I do not understand that hypnotism is suggestion in the true sense. I believe that everyone uses suggestion; but when you render a patient unconscious, put him in to the true hypnotic condition, then you make an impression upon him of an entirely different character. There is always a class of patients with whom this is repeated over and over again. We hypnotize certain patients continuously because we find it easy to do so, and I maintain that that constant brain action is injurious. I believe that hypnotism will in time injure the patient, and will not accomplish the good that is hoped for and expected.

\section{A STUDY OF THE STIGMATA OF DEGEN. ERACY AMONG THE AMERICAN CRIMINAL YOUTH.}

Presented to the Section on Neurology and Medical Jurisprudence at the Forty-eighth Anuual Meeting of the American Medical Association held at Philadelphia, June 1-4, 189 .

BY EUGENE S. TALBOT, M.D., D.D.S.

CHICAGO. ILL.

The present contribution results from studies on young criminals made during 1895-96 at the State reformatories at Pontiac, Ill., and Elmira, New York. The investigation concerns especially the stigmata of the head and face. The stature and weight were noted, but other anthropometric data were not specially considered, as measurements had to be entrusted to others. It was therefore deemed advisable to avoid as far as possible elements of error concomitant on extensive detailed anthropometry. Only simple measurements easily obtained with accuracy were made. Inasmuch as facial and cranial development are, as a rule, most directly co-related with moral and intellectual evolution it was deemed natural that they should furnish sufficient data for discussion in an article of the present scope.

Since the inquiry dealt only with the physical stigmata of the head and face, the youngest inmates were, for obvious reasons (immature jaw and face development) excluded from consideration. The object of the inquiry was to determine the extent to which the 